\title{
Water, Ecosystems, and Society: a confluence of disciplines
}

\author{
Jayanta Bandyopadhyay, Sage, 2009
}

Reviewed by M N Murty, Institute of Economic Growth, Delhi-IIO 007, India

Resources, Energy, and Development 6(2): 95-96

Water resources constitute a vital component of ecosystems of the earth. They are being threatened by unsustainable use with its evergrowing ecological foot prints far exceeding its carrying capacity. This book by Professor Jayanta Bandyopadhyay, a well known ecologist, while arguing for a need for interdisciplinary approaches, explains the role of different disciplines in the ecologically sustainable management of water resources. It highlights the importance of interdisciplinary approaches in dealing with floods, a curse as well as a benefactor, especially in many developing countries including India and interlinking the rivers to avoid floods and ensure more equitable distribution of water, both geographically and temporally. This book also rightly points out that the economic valuations of water system services require interdisciplinary approaches.

This book underscores the importance of developing the knowledge of water systems in an interdisciplinary perspective for developing strategies to ensure the sustainable supply of ecological services they provide. It observes that there is a disconnect between water systems knowledge and water resource development in India. There is an urgent need for understanding the past growing inter-disciplinary knowledge on water systems and the emerging paradigm shift in their management all over the world.
This book very importantly points out that the growing awareness of water as a human right, difficulties in defining and implementing property rights on water, tradeoffs between many ecosystem services provided by water, the valuation of flows of these services for justifying costs of water conservation, the recognition of environmental flow requirements in ground and surface water, and so on, are important components of this new paradigm. For taking advantage of the knowledge of new developments in water resource management, this book recommends certain themes for water resource research in India. These include generation of eco-hydrological knowledge of the surface and groundwater systems, social and economic valuation of water resource services, mechanisms to deal with hydrological events like floods and droughts, and water laws and entitlements.

The book provides a good description of ecohydrological perspectives on floods. It explains the river-floodplain ecosystem interactions and ground water and surface water interactions. It describes comprehensively the multiple benefits from floods, which may over compensate damages to house property and crops and loss of lives. For a curious reader, this book also provides useful information about the topology of floods in India, past and current strategies 
followed for flood control, the future strategies with a paradigm shift, and improved knowledge.

Economic valuation of ecological services of water resources is important for efficient allocation of water for different private good type of uses - drinking, industrial, hydropower, agricultural, fisheries, and navigation - and public good type of uses - recreation, aquatic life, and waste disposal. There are markets for private good services of water, which are usually imperfect in the developing countries, so that market prices may not represent the true value of water in respective uses. The markets are absent for public good type of services, so that there are no prices to guide resource allocation decisions favouring allocation of water to public good, vis-à-vis, private good type of services. In either case, there is a need for estimating value of water in different uses and the methods of valuation are interdisciplinary as correctly observed in this book. Suppose, one wants to estimate the health effects of improved water quality of a river. It first requires an epidemiologist to fund out the reduction in the incidence of water borne diseases with the improved water quality and an economist to find out the monetary value (saving in the cost of illness) of the reduction of incidence of diseases.

The chapter on the river-link project in India provides very useful information for public consumption and debate about such a prestigious project of Indian government. The project linking glacier-fed Himalayan water systems to rain-fed southern water systems in India could result in equitable access to water temporally and geographically in India and could reduce uncertainty in water supply particularly in peninsular India. The gradually unfolding information of adverse effects of global warming on Indian monsoon and the apathy of world community to adequately address to the climate change mitigation in the current scenario make this project a necessity in India. This project could be a strategic adaptation method for climate change induced monsoon uncertainty in the country. However, this book rightly points out that final decision of this project has to be taken only after preparing a thorough techno-economic feasibility study highlighting technological challenges, environmental, and socio-economic problems this project may bring out. 